\title{
Ensino de Matemática para surdos: mapeamento de pesquisas sobre resolução de problemas
}

\author{
Mathematics teaching for deaf: mapping research on problem solving
}

\author{
Fabrício Andrade Pinheiro \\ Salvador Cardoso Silva Muniz \\ Jurema Lindote Botelho Peixoto \\ Zulma Elizabete de Freitas Madruga
} \begin{abstract}
de Qualis A1 a B2, portal de teses e dissertações da CAPES, Google Acadêmico e Scielo, utilizando-se para tanto as palavras-chave 'inclusão de surdo', 'inclusão e resolução de problemas' e 'situações problemas'. Após filtragem dos resultados, foram encontrados seis artigos que fizeram parte do corpus de análise. Os resultados mostraram que a inclusão não está ocorrendo de forma efetiva, pois 0 professor ainda não está preparado para atender alunos surdos e, consequentemente, ensinar Matemática para esses estudantes. Destaca-se também o número reduzido de pesquisas que tratam sobre a inclusão de surdos tendo a resolução de problemas como foco.
\end{abstract}

Resumo: Este artigo tem como objetivo analisar pesquisas acadêmicas que tratam da inclusão de estudantes surdos e enfocam a resolução de problemas. Para tanto foi utilizado o mapeamento na pesquisa educacional como procedimento metodológico. Foram realizadas buscas em revistas

Palavras-chave: Ensino de Matemática. Inclusão de surdos. Resolução de problemas.

Abstract: This paper aims to analyze academic research that addresses the inclusion of deaf students and focuses on problem solving. For this, mapping in educational research was used as a methodological procedure. Searches were conducted in Qualis A1 to B2 journals, CAPES thesis and dissertations portal, Academic Google and Scielo, using the keywords 'inclusion of deaf people', inclusion and problem solving. 'and' problem situations'. After filtering the results were found six articles that were part of the corpus of analysis. The results showed that inclusion is not occurring effectively, because the teacher is not yet prepared to attend deaf students and, consequently, teaching Mathematics for these students. It is also worth noting the limited number of researches that deal with the inclusion of deaf people, focusing on problem solving.

Keywords: Mathematics Teaching. Inclusion of deaf people. Problem solving.
Fabrício Andrade Pinheiro Licenciado em Matemática pela Universidade Estadual de Santa Cruz (UESC). Professor do Centro Educacional Ubaitabense. Bahia, Brasil. iD orcid.org/0000-0001-5364-8503 $\triangle$ fabricioandrade_02@hotmail.com Salvador Cardoso Silva Muniz Mestre em Educação Matemática pela Universidade Estadual de Santa Cruz (UESC). Professor na Escola Municipal Reunidas Castro Alves, na cidade de Jiquiriçá. Bahia, Brasil.

iD orcid.org/0000-0002-0124-4571 $\bowtie$ umsalvadoor@gmail.com

Jurema Lindote Botelho Peixoto Doutorado em Difusão do Conhecimento pela Universidade Federal da Bahia (UFBA). Professora do Programa de Pós-Graduação em Educação Matemática da Universidade Estadual de Santa Cruz (UESC). Bahia, Brasil.

iD orcid.org/0000-0002-5648-7001

$\bowtie$ peixotojurema@gmail.com

Zulma Elizabete de Freitas Madruga Doutora em Educação em Ciências e Matemática pela Pontifícia Universidade Católica do Rio Grande do Sul (PUC-RS). Professora da Universidade Federal do Recôncavo da Bahia (UFRB), campus Amargosa. Professora Colaboradora do Programa de Pós-Graduação em Educação Matemática da Universidade Estadual de Santa Cruz (UESC)

(iD) orcid.org/0000-0003-1674-0479

$\checkmark$ betefreitas.m@gmail.com

Recebido em 18/07/2019 Aceito em 11/09/2019 Publicado em 01/01/2020 


\section{Introdução}

O tema inclusão educacional surge no Brasil na década de 1980 e 1990, ganhando força após a conferência mundial sobre necessidades educativas especiais em 1994, em Salamanca, Espanha. Em 1996, a Lei de Diretrizes e Bases da Educação Nacional (BRASIL, 1996) apresenta um capítulo próprio, com abordagens sobre profissionalização, professores, currículo, apoio técnico e financeiro do poder público, trazendo uma nova visão de Educação Especial para 0 ensino público. Os estudantes com necessidades especiais poderiam ser matriculados preferencialmente na escola comum.

A Lei Brasileira de Inclusão - LBI (BRASIL, 2015), teve seu texto apresentado ao senado pela primeira vez em 2003, anos depois, passou por correções, por consultas e audiências públicas; somente em 2015, o projeto foi sancionado pela presidência. Essa lei concebe a deficiência a partir de uma abordagem social:

A deficiência deixa de ser um atributo da pessoa e passa a ser o resultado da falta de acessibilidade que a sociedade e o estado dão as características de cada um, ou seja, a LBI veio para mostrar que a deficiência está no meio, não nas pessoas, então quanto mais acessos e oportunidades uma pessoa dispõe, menores serão as dificuldades consequentes de sua característica. (GABRILLI, 2016, p.13)

No contexto educacional, as barreiras também devem ser suprimidas, para que os estudantes com deficiência - sensoriais, motoras e/ou intelectuais -, transtorno do espectro do autismo ou altas habilidades/superdotação (BRASIL, 2008) possam participar das atividades com igualdade de oportunidades. Particularmente, muitos professores sentem-se incapazes de lidar com a demanda de estudantes surdos em sua sala de aula (PEIXOTO, 2015a; MUNIZ, 2018), as barreiras comunicacionais impedem uma melhor interação, apesar da presença dos tradutores e intérpretes de Língua Brasileira de Sinais (TILS), para traduzir os conhecimentos em sala de aula. Nesse sentido, esse estudo torna-se relevante, pois intenta-se conhecer pesquisas que subsidiem professores na promoção de uma educação de qualidade, preservando seus direitos de acesso e participação na sociedade e escola. Em decorrência, faz-se necessário verificar quais os avanços podem trazer para o ensino e a aprendizagem de Matemática, especificamente no que tange à resolução de problemas, surgindo, a partir daí, a seguinte questão-problema: "Como se apresentam as pesquisas que tratam da inclusão de estudantes surdos e enfocam a resolução de problemas?". 


\section{Sobre a inclusão educacional do estudante surdo}

A Lei Brasileira de Inclusão (BRASIL, 2015) considera que a deficiência está no meio, não nas pessoas. Para tanto, apresenta seu conceito baseado no modelo social, a pessoa com deficiência "é aquela que tem impedimento de longo prazo de natureza física, mental, intelectual ou sensorial, o qual, em interação com uma ou mais barreiras, pode obstruir sua participação plena e efetiva na sociedade em igualdade de condições com as demais pessoas" (BRASIL, 2015, Art. $\left.2^{\circ}\right)$.

Nesse sentido, Vygostsky (2007) afirma que os indivíduos com necessidades especiais têm um potencial de desenvolvimento cognitivo normal, alcançado pelas interações e intervenções do professor por meio de estímulos e instrumentos, ou seja, toda criança tem capacidade de aprender, e o que irá proporcionar esse aprendizado é a mediação.

Para que a educação inclusiva seja efetivada, ainda se tem muito que avançar nas condições do ambiente escolar, seja na garantia de recursos financeiros, no currículo, na formação dos profissionais voltada à inclusão, entre outras melhorias. E quando se trata de estudantes surdos, não basta apenas conhecer suas características ou um pouco da Língua Brasileira de Sinais (Libras) para desenvolver o processo de aprendizagem, mas é necessário ir além deste ponto de partida. É colocar-se no lugar desse estudante, experimentar o mundo sem a audição, para, dessa forma, tentar buscar maneiras de mediar o conhecimento que realmente incluam esses estudantes. Isso é importante para que se tenha uma aprendizagem com mais significado.

A pessoa surda, considerada nesse estudo, é aquela que "por ter perda auditiva, compreende e interage com o mundo por meio de experiências visuais, manifestando sua cultura principalmente pelo uso da Língua Brasileira de Sinais - Libras" (BRASIL, 2005, Art. $2^{\circ}$ ). Dessa forma, o estudante surdo não compartilha uma língua com seus colegas e professores, estando assim em desigualdade nesse aspecto, um dos caminhos encontrados pela legislação foi garantir a presença do profissional TILS (BRASIL, 2002, 2005). Sem esse auxílio, a apreensão dos conhecimentos trabalhados pode ficar comprometida, pois os professores não dão conta sozinhos de mediar o conhecimento em duas línguas, conforme afirmam Botelho (1998) e Lacerda (2000).

É necessária a utilização de um tripé educacional no qual estão envolvidos o domínio da Libras, o conhecimento matemático e uma metodologia apropriada, ou, pelo menos, o primeiro e o terceiro destes (OLIVEIRA, 2005). Peixoto (2015a) aplicou situações-problema para um aluno do $7^{\circ}$ ano do Ensino Fundamental buscando explorar a emergência e manutenção da Zona de 
Desenvolvimento Proximal ${ }^{1}$ (ZDP), na interação e comunicação entre professor, intérprete e um aluno surdo, em uma atividade matemática. Dessa forma constatou que a criação e manutenção da comunicação depende diretamente da qualidade da negociação de significados dos sujeitos envolvidos na interação. Para tanto, o professor precisa utilizar recursos variados que contemplem a experiência visual do estudante surdo e a sua forma de comunicação.

Nesse sentido, Muniz (2018) apontou em sua pesquisa aspectos que comprometem 0 ensino da Matemática para alunos surdos, como a prática de "ditar" atividades e vídeos sem legendas, falta de materiais manipuláveis, explicação rápida do professor de Matemática que atrapalha a interpretação do TILS para o aluno, entre outras situações.

Para promover o ensino e a aprendizagem considerando estudantes surdos é necessário que o professor de Matemática conheça suas especificidades, pois disciplinas "estanques" sem articulação umas com as outras no curso de licenciatura, não dão base para a dinâmica de uma sala de aula com alunos surdos. Os futuros professores precisam reconhecer a Libras como a primeira língua desses estudantes e aprender a desenvolver metodologias que incluam esses alunos, efetivamente, na prática (MUNIZ, 2018)

Além disso, Muniz, Peixoto e Madruga (2018), com base em uma pesquisa qualitativa a partir da tríade professor, aluno surdo e intérprete, mostram os desafios encontrados nas aulas de Matemática, utilizando alguns autores como Borges (2013), Muniz (2018), Nunes et al. (2001) e Peixoto (2015b). Apontam falhas encontradas nas escolas com relação ao ensino de Matemática e possibilidades metodológicas para o professor que atua com os estudantes surdos.

Os autores destacam três desafios: o primeiro está na formação dos professores que atuam com alunos surdos e a falta de formação continuada específica; o segundo é o do intérprete, que acaba assumindo a responsabilidade de ensinar Matemática, sem a formação para tal, daí a necessidade de um planejamento em conjunto, pois o TILS poderia ajudar a pensar em metodologias de ensino mais adequadas aos surdos, por estar bem próximo das dificuldades dos mesmos; o terceiro é a escola, que precisa abraçar realmente a causa da inclusão, pensando em formas de adaptar o currículo de acordo com as necessidades dos alunos surdos, para

\footnotetext{
${ }^{1}$ Distância entre o nível de desenvolvimento real que se costuma determinar através da solução independente de problemas, e 0 nível de desenvolvimento potencial, determinado através da solução de problemas sob a orientação e um adulto ou em colaboração com companheiros mais capazes, conforme Vygotsky (2007, p. 97).
} 
proporcionar uma interação eficaz. Entende-se que dessa maneira é possível que a escola seja realmente uma escola inclusiva.

Analisando os esquemas dos estudantes surdos, e enfatizando suas ações em Libras, gestos e produções escritas durante a resolução de problemas de divisão, Peixoto (2015a) buscou os conteúdos desses esquemas, ou seja, os conceitos e teoremas-em-ação mobilizados na ação cognitiva. Ao mesmo tempo, observou como as práticas em Libras vão influenciando tais esquemas. Os achados mostraram que estudantes surdos usam vários esquemas conjugando Libras e gestos, e o professor pode aproveitar esses esquemas no processo de ensino.

\section{Sobre resolução de problemas}

Na História da Matemática sempre existiram situações-problema para serem resolvidas por meio de números e cálculos, na verdade os números surgiram com a necessidade de contar animais, objetos, alimentos, ou seja, surgiu para resolver problemas do cotidiano, mas nos processos ensino e de aprendizagem, o que predominou no princípio foi a memorização e repetição.

Em 1945, Polya lançou um livro chamado $A$ arte de resolver problemas dando um novo rumo no processo de ensino e de aprendizagem. No Brasil, somente entre 1996 e 1998 com a criação da Lei de Diretrizes e Bases da Educação Nacional (BRASIL, 1996) e com os Parâmetros Curriculares Nacionais - PCN (BRASIL, 1998), a discussão sobre resolução de situaçõesproblema no ensino da Matemática passou a ganhar força. Os PCN (BRASIL, 1998) apontam a Resolução de Problemas como o eixo norteador, como o ponto de partida para o ensino dos conhecimentos da Matemática. A Base Nacional Comum Curricular — BNCC (BRASIL, 2017) em sua última versão mostra que o processo matemático de resolução de problemas pode configurar como objeto e estratégia para a aprendizagem ao longo de todo o Ensino Fundamental, e pode desenvolver competências como raciocínio, argumentação e representação, que são fundamentais para o letramento matemático.

A Matemática sempre foi vista como uma ciência desafiadora, nesse sentido somente memorizar e reproduzir não estimula a aprendizagem; o estudante precisa aprender a pensar, sentir-se desafiado a querer buscar uma resolução, desse modo, a utilização da resolução de situações-problema pode ser um grande facilitador nesses processos, afirma Dante (2000). 
Pesquisadores como Polya (1995), Allevato (1999), Dante (2000), Onuchic (1999), Krulik (1997), Onuchic e Allevato (2011), dedicaram-se a desenvolver maneiras para mostrar a importância da resolução de problemas e como levar isso para os estudantes. Polya (1995, p. 6) afirma que "o problema pode ser modesto, mas se ele desafiar a curiosidade e colocar em jogo as faculdades inventivas, quem o resolver por seus próprios meios experimentará a tensão e gozará o triunfo da descoberta".

Esse autor propõe quatro fases para resolver um problema que, se forem levadas em consideração, poderão melhorar a capacidade de resolver problemas, a saber: (1) Compreensão do problema, ou seja, é a percepção dos objetivos solicitados no enunciado; (2) Estabelecimento de um plano, relação entre as incógnitas e os dados do problema; (3) Execução do plano, fazer o que planejou resolvendo o problema; e (4) Retrospecto, fase onde se revisa e discute a eficácia do planejado.

Nessa abordagem, o professor assume a resolução de problemas como um conteúdo a ser ensinado, utilizando estratégias e métodos próprios. De acordo com Allevato e Onuchic (2014), mais duas perspectivas relativas à metodologia de resolução de problemas podem ser identificadas: i) ensinar Matemática para resolver problemas, quando o professor ensina os conteúdos e seus procedimentos técnicos, esperando que os estudantes os apliquem em outros contextos; ii) Ensinar Matemática via resolução de problemas, quando os problemas são propostos visando desenvolver o pensamento matemático, e consequentemente, os conteúdos são ensinados e trabalhados.

Baseado nessa última perspectiva, Onuchic e Allevato (2008) desenvolveram uma metodologia de ensino-aprendizagem-avaliação a partir da resolução de problemas, considerando que 0 ensino e a aprendizagem caminham juntos durante todo o processo. Essas autoras definem "problema" como um exercício que não se sabe fazer, mas que se tem interesse em resolver. A partir daí propuseram uma metodologia que também devem seguir passo a passo e é dividida em dez fases, são elas: (i) preparação do problema; (ii) leitura individual; (iii) leitura em conjunto; (iv) resolução de problema; (v) observar e incentivar; (vi) registro da resolução na lousa; (vii) plenária; (viii) busca de consenso; (ix) formalização do conteúdo; e (x) proposição e resolução de novos problemas. Nesse processo, os alunos podem vislumbrar novos problemas.

Na temática de resolução de problemas, ainda se verifica a ênfase na formulação de problemas. No contexto dos anos iniciais, Chica (2001, p. 151) enfatiza que 


\begin{abstract}
quando o aluno cria seus próprios textos de problemas, ele precisa organizar tudo que sabe e elaborar o texto, dando-Ihe sentido e estrutura adequados para que possa comunicar o que pretende. Nesse processo, aproximam-se a língua materna e a matemática, as quais se complementam na produção de textos e permitem 0 desenvolvimento da linguagem específica. $O$ aluno deixa então de ser um resolvedor para sérum propositor de problemas, vivenciando o controle sobre o texto e as idéias matemáticas.
\end{abstract}

Alguns autores como Malheiros (2004) e Barbosa (2001), tratam a resolução de problemas como uma estratégia de ensino, mas a mesma é também vista como uma maneira de aprendizagem, pois o estudante precisa aprender a aprender, desenvolver raciocínio-lógico, buscar estratégias para as diversas situações do dia a dia e é isso que a resolução de situaçõesproblema propõe.

A abordagem da resolução de problemas como metodologia, à princípio, pode ser compreendida como uma mera prescrição de métodos a serem desenvolvidos na aula, visando ao sucesso da aprendizagem. Entretanto, cada sala de aula é formada por uma heterogeneidade de estudantes e cada professor é único em suas experiências, saberes e crenças, assim, os resultados do desenvolvimento dessa perspectiva não podem ser os mesmos, nem a própria abordagem é a solução para todos os problemas do ensino. 0 professor deve ter autonomia teórica para refletir o que lhe é mais adequado utilizar na sua atuação.

\title{
4 Procedimentos metodológicos
}

Esta pesquisa é de cunho qualitativo (BOGDAN e BIKLEN, 1994), na qual foi utilizado como princípio metodológico o mapeamento na pesquisa educacional, segundo Biembengut (2008). A ideia de mapeamento é a de ser um guia para se chegar a algum conhecimento, construído a partir da seleção e organização de dados, levando-se em conta o que for mais significativo e relevante sobre determinado tema.

Para a escrita do presente artigo foram analisadas 75 revistas qualificadas pela Coordenação de Aperfeiçoamento de Pessoal de Nível Superior (CAPES), sendo 12 revistas no estrato A1 do Qualis, 19 revistas no A2, 18 revistas no B1 e 25 revistas no B2. Optou-se pelas revistas $A 1$ a $B 2$ por configurarem as quatro categorias mais bem avaliadas pelas CAPES na classificação de periódicos do quadriênio 2013-2016. Destas, foram analisadas 75 revistas da Área de Ensino, as quais aceitavam artigos no âmbito da Educação Matemática. 
Em todas as buscas, a palavra-chave procurada no primeiro momento foi "inclusão de surdos", logo após passou-se a filtrar utilizando "inclusão e resolução de problemas", a partir daí foi iniciada a separação do seria relevante e significativo para esta pesquisa em um esquema de mapa. A pesquisa buscou artigos publicados nos últimos dez anos (2008-2018), pois o intuito era verificar como as pesquisas recentes expressam a temática em questão.

Foi encontrada uma quantidade considerável de pesquisas relacionadas a "inclusão de surdos" no ensino da Matemática, na Física e nos anos iniciais do Ensino Fundamental, a maioria tratando de Geometria, especificamente. No entanto, este não era o foco deste estudo, então, utilizou-se apenas os resultados para inclusão de surdos e resolução de situações-problema, caso este em que foram apenas dois artigos ${ }^{2}$, como mostra o Quadro 1 :

Quadro 1: Artigos encontrados em revistas de Qualis A1 a B2

\begin{tabular}{cl}
\hline Artigos & Referência \\
\hline P1 & $\begin{array}{c}\text { RODRIGUES, Rosiane da Silva; GELLER, Marlise. Desenvolvimento } \\
\text { conceitual do aluno surdo na resolução de problemas aditivos: uma } \\
\text { avaliação diagnóstica. Educação Matemática em Revista-RS, Rio } \\
\text { Grande, v. 3, n. 18, p. 90-106, 2017. }\end{array}$ \\
\hline P2 & $\begin{array}{l}\text { CRUZ, Tatyane Veras de Queiroz Ferreira; LABRES, Síntria Labres. } \\
\text { Que fatores interferem na resolução de problemas de multiplicação por } \\
\text { crianças surdas: a língua ou os suportes de representação? Jornal } \\
\text { Internacional de Estudos em Educação Matemática, São Paulo, v. 7, } \\
\text { n. 2, p. 65-88, 2014. }\end{array}$ \\
\hline
\end{tabular}

Fonte: Elaboração dos Autores

Outra busca foi realizada no Banco de Dissertações e Teses da CAPES, no qual foi incluída a expressão exata: "inclusão de surdos". Foram encontrados 38 resultados; a pesquisa foi refinada para os anos de 2008 a 2018, reduzindo para 32 resultados. Logo após foi selecionada a "Grande área de conhecimento para Ciências Humanas e Multidisciplinar", reduzindo, assim, para 26 resultados; quando selecionada a "área de conhecimento" para Educação, Ensino e Ensino de Ciências e Matemática, o resultado passou a ser 17. Refinando ainda mais a pesquisa para a "área de concentração" Ensino de Matemática, Educação Brasileira, Educação Matemática, Educação em Ciências, Educação em Ciências e Matemática e Ensino de Ciências e Matemática, o resultado passou a ser sete.

\footnotetext{
2 Optou-se por nomear as pesquisas encontradas da seguinte forma: P1, P2, P3 etc.
} 
Mesmo assim foram encontrados resultados para estudos de emancipações de sinais (2); processos de inclusão em atividades para alunos surdos de uma maneira geral (2); inclusão de surdos no ensino de Matemática de maneira geral (2); atuação de intérprete em sala de aula (1). Sendo assim, sem mais resultados para o ensino de Matemática para surdos com foco na resolução de situações-problema.

Uma terceira pesquisa foi feita no "Google Acadêmico" com a palavra-chave "inclusão de surdos", encontrando assim 888 resultados, refinando um pouco mais essa pesquisa para "inclusão de surdos" + "situações problemas" foram encontrados 31 resultados, após analisar cada um desses 31 trabalhos, foi encontrado um artigo que tratava dos alunos surdos na resolução de situações-problema, que foi um dos mesmos artigos encontrado na primeira busca, o artigo denominado P2.

Por fi,m uma quarta pesquisa foi realizada, com mesma palavra-chave, agora na plataforma Scientific Electronic Library Online (Scielo), e foi encontrado um artigo, conforme Quadro 2.

Quadro 2: Artigo encontrado no Scielo

\begin{tabular}{cc}
\hline Artigo & \multicolumn{1}{c}{ Referência } \\
\hline P3 & FAVERO, Maria Helena; PIMENTA, Meireluce Leite. Pensamento e \\
& $\begin{array}{l}\text { Linguagem: a língua de sinais na resolução de problemas. Psicologia: } \\
\text { Reflexão e Critica, Porto Alegre, v. 19, n. 2, p. 225-236, 2006. }\end{array}$ \\
\hline
\end{tabular}

Fonte: Elaboração dos Autores

Pode-se observar que este artigo não contempla o que foi inicialmente previsto, que seriam somente as pesquisas recentes, realizadas nos últimos 10 anos (2008-2018), no entanto, como a busca apresentou um número reduzido de trabalhos, e esta pesquisa adequa-se perfeitamente às pretensões de análise deste estudo - inclusão de surdos e resolução de problemas -, foi decidido incluir o artigo P3, publicado em 2006, no corpus de análise desta pesquisa.

Foi necessário retornar às 75 revistas qualificadas pela CAPES, buscando proximidade de alguns artigos com a temática estudada, para isso, modificou-se uma das palavras-chaves, no intuito de encontrar mais algumas pesquisas que pudessem servir para esta análise. Agora usando a palavra-chave "situações-problema", foi refeita a pesquisa. A partir desta nova busca, foram 
selecionados mais três artigos - P4, P5 e P6 - em revistas dos estratos A1 a B2 do Qualis/CAPES, conforme Quadro 3.

Com essa nova busca, o corpus de análise ficou constituído de seis pesquisas, conforme mostra o Quadro 3.

Quadro 3: Pesquisas encontradas nas revistas de Qualis A1 a B2

\begin{tabular}{cl}
\hline Artigo & \multicolumn{1}{c}{ Referência } \\
\hline P4 & $\begin{array}{l}\text { BORGES, Fábio Alexandre; NOGUEIRA, Clélia Maria Ignatius. Das } \\
\text { palavras aos sinais: o dito e o interpretado nas aulas de Matemática } \\
\text { para alunos surdos inclusos. Perspectivas da Educação Matemática, } \\
\text { Campo Grande, v. 9. N. 20, p. 479-500, maio/ago. 2016a. }\end{array}$ \\
\hline P5 & $\begin{array}{l}\text { SALES, Elielson Ribeiro; PENTEADO, Miriam Godoy; MOURA, } \\
\text { Amanda Queiroz. A negociação de sinais em libras como possibilidade } \\
\text { de ensino e de aprendizagem de Geometria. Bolema, Rio Claro, v. 29, } \\
\text { n. 53, p. 1268-1286, dez. 2015. }\end{array}$ \\
\hline P6 & $\begin{array}{l}\text { BORGES, Fábio Alexandre; NOGUEIRA, Clélia Maria Ignatius. O } \\
\text { ensino e aprendizagem de Matemática para surdos inclusos: o que } \\
\text { dizem intérpretes de Libras? Educação Matemática em Revista-RS, } \\
\text { Rio Grande, v. 2, n. 17, p. 121-134, 2016b. }\end{array}$ \\
\hline
\end{tabular}

Fonte: Elaboração dos Autores

Após a busca e seleção dos artigos que fizeram parte do corpus da pesquisa, foi realizado o processo de análise dessas obras. Para essa análise, foram elencadas as seguintes categorias a priori: aportes teóricos; contexto da pesquisa; problemas investigados/interesse da pesquisa; metodologia; principais resultados e contribuições para o avanço do tema na área.

Nessa etapa da pesquisa buscou-se compreender os resultados obtidos em cada um dos artigos, considerando suas relações.

\section{Resultados e discussão}

Para facilitar a análise e entendimento dos dados, foram elencadas categorias a priori, conforme mencionado anteriormente. Nesta seção são apresentadas tais categorias, buscandose relações entre as pesquisas analisadas, pontos convergentes e divergentes em cada um dos casos. 


\subsection{Dos aportes teóricos}

No cenário brasileiro são poucas as bases teóricas relacionadas à educação de estudantes surdos, quando se trata de formas de inclusão nas salas de aula nos processos de ensino e de aprendizagem. O artigo P1 apresenta uma investigação feita para compreender os fatores que estão envolvidos no processo de resolução de problemas aditivos com base na teoria dos campos conceituais de Gerárd Vergnaud. Essa teoria permite prever formas mais eficientes para ensinar e trabalhar os conteúdos matemáticos.

No artigo P2, Cruz e Labres (2014) utilizam como base as ideias de Razuck, Tacca e Tunes (2007) ao afirmarem que a criança deficiente tem seu organismo reestruturado para compensar os efeitos da deficiência, então, a criança surda possui essa compensação em outras formas de comunicação.

No Artigo P3, Fávero e Pimenta (2006) utilizam-se das ideias de Mead (1963), o qual defende que o pensamento é a interiorização da conversação por gestos, ou seja, a compreensão dos diálogos por gestos é a própria essência do pensamento, esses gestos são símbolos com 0 mesmo significado para todos os indivíduos envolvidos na comunicação, portanto geram a mesma atitude. Nesse sentido, Mead (1963) defende a não dicotomia entre pensamento e linguagem, entendendo que quando se misturam conversação gestual e verbal há uma melhor partilha de significados.

O Artigo P4 trabalha com o dito e o interpretado pelos alunos surdos, e os autores Borges e Nogueira (2016a) usam como base teórica as ideias de Rodrigues (2005), o qual afirma que a escola historicamente foi fonte de exclusão para vários estudantes com deficiência, que foram confundidas com falta de motivação, indisciplina, falta de inteligência e ritmo.

Os autores do artigo P5, Sales, Penteado e Moura (2015), apresentam como referência teórica Sales (2013), o qual diz que a resolução de problemas aditivos e o ensino de geometria, por meio de recursos visuais e libras permitem uma comunicação favorável com grupos de alunos, proporcionando aprendizado nos conceitos matemáticos.

O Artigo P6 traz ideias que visam o aprendizado do aluno surdo com o auxílio do intérprete de libras e para essa base teórica, Borges e Nogueira (2016b) utilizam Moreira (1997), que afirma que caso não ocorra interação comunicativa entre professor e aluno, não pode nem se quer cogitar a possibilidade de ser uma aula. 
Nesta análise a intenção foi verificar o embasamento teórico dos trabalhos e foi percebido que os seis artigos tiverem como bases teóricas autores diferentes. No entanto, os artigos P1, P2 e P3 seguiram uma mesma linha de pensamento, trabalhando com autores que visam a melhor maneira de aprendizado utilizando-se da Psicologia. Em P1, os autores assumem a teoria de Vergnaud, sendo que em P2 e em P3, este autor também foi citado para falar sobre Psicologia, mas os autores não assumem essa teoria como base para suas pesquisas.

Além disso, todos os artigos analisados procuram melhorias para a comunicação entre 0 professor e o aluno surdo, buscando maneiras para que aconteça uma interação com aprendizado, excluindo totalmente $o$ isolamento desses estudantes, assim como pode-se observar na pesquisa de Peixoto (2015a).

\subsection{Do contexto da pesquisa}

Um dos pontos analisados nesses trabalhos referem-se aos contextos de pesquisa, ou seja, local, turma, público-alvo, entre outros, com a intenção de saber onde estão sendo aplicados tais estudos.

O artigo P1 trata de uma investigação aplicada com alunos do Ensino Fundamental de $3^{\circ}$ e $4^{\circ}$ anos, em uma instituição especializada de alunos surdos na região metropolitana de Porto Alegre (RS), sendo um total de sete alunos, três do $3^{\circ}$ ano e quatro do $4^{\circ}$ ano, todos os estudantes da mesma sala devido à organização da escola. A atividade foi composta por oito situaçõesproblema envolvendo adição e subtração, questões tanto em língua portuguesa, quanto em Libras.

Já o artigo P2 fez a investigação em uma escola também de Ensino Fundamental pública, mas não especializada, na cidade de Recife (PE), alcançando 88 alunos entre ouvintes e surdos. Esses, foram alocados em quatro grupos, sendo G1, composto por surdos sem instruções sobre a multiplicação; G2, constituído por surdos com instruções sobre a multiplicação; G3, formado por ouvintes com instruções sobre a multiplicação; e G4, composto por ouvintes sem instruções sobre a multiplicação. Todos os alunos, ouvintes e surdos, resolveram três situações-problema, uma escrita na Língua Portuguesa com todas as regras gramaticais; outra escrita na interlíngua, que é a escrita dos surdos nos anos iniciais; e a terceira atividade foi sinalizada em Libras.

No artigo P3 a investigação foi realizada em uma escola de Ensino Fundamental dos anos iniciais de Educação de Jovens e Adultos, no Distrito Federal (DF), na qual participaram alunos 
surdos entre 18 e 30 anos. Foi aplicada uma atividade que fora dividida em três fases: avaliação das competências matemáticas dos sujeitos sobre a lógica do sistema de numeração; pesquisa em Libras para expressões "n a mais que" e "n a menos que", em comparação de conjuntos; e investigação de resoluções de problemas matemáticos comparando a resolução individual com e sem intervenção.

O Artigo P4 investigou o ensino de Matemática para surdos em uma sala de aula de Ensino Médio da rede pública, em turma de $9^{\circ}$ ano, onde estudavam 32 alunos, sendo dois alunos surdos com acompanhamento de um intérprete, no estado do Paraná. Buscou-se identificar as diferenças significativas entre o que a professora explicava e o que os intérpretes passavam para os alunos surdos.

Em P5, a investigação ocorreu em uma escola pública do Ensino Fundamental, localizada num bairro da periferia do município de Rio Claro (SP). A escola atende alunos com deficiência de um modo geral, mas se destaca no trabalho desenvolvido com os alunos surdos. A investigação foi realizada em uma sala de $5^{\circ}$ ano onde estudavam 12 alunos, sendo oito surdos e quatro ouvintes; com ensino de figuras geométricas, foi realizada uma negociação de sinais para denominar as figuras ausentes de significados nos dicionários de Libras.

Na pesquisa P6, a investigação foi feita diretamente com quatro profissionais intérpretes de libras que atuavam em escolas públicas, no estado do Paraná (PR), além da formação de intérpretes, possuíam formação em Matemática (1), formação em Pedagogia (2) e formação em Geografia (1). Foi feita uma entrevista semiestruturada sobre diversos assuntos em áudio e transcrita pelos pesquisadores. A ideia era buscar o conhecimento que tinham sobre o ensino da Matemática para alunos surdos de acordo com suas experiências na escola inclusiva.

Todas as pesquisas foram realizadas na rede pública de ensino, em diferentes regiões do Brasil, sendo P1 (crianças), P2 (crianças), P3 (jovens e adultos) pesquisas diretamente com alunos trabalhando com resoluções de problemas. Para Onuchic e Allevato (2011, p. 82), a "resolução de problemas desenvolve poder matemático nos alunos, ou seja, capacidade de pensar matematicamente, utilizar diferentes e convenientes estratégias em diferentes problemas, permitindo aumentar a compreensão dos conteúdos e conceitos matemáticos", além disso, ainda coloca o foco da atenção dos alunos sobre as ideias matemáticas e sobre as diferentes possibilidades de contextualização. 
Já os artigos P4 e P5 trataram de investigações tanto com alunos quanto com professores e intérpretes. P5 visou a negociação entre as três categorias no estabelecimento de sinais inexistentes para os surdos e P4 buscou as diferenças de comunicações entre aluno-professorintérprete.

\subsection{Dos problemas investigados/interesse da pesquisa}

$\mathrm{O}$ artigo P1, P2 e P3 tomaram como foco principal para o questionamento a resolução de problemas, sejam eles aditivos ou multiplicativos. P2 e P3 buscaram mostrar e entender as falhas ao ensinar os alunos surdos em uma escola inclusiva; já P1 procurou diagnosticar como essas falhas estão sendo resolvidas, tentando identificar se as dificuldades dos alunos surdos em interpretar surgem por conta da linguagem, ou seja, no geral os trabalhos buscaram uma solução para melhorar o aprendizado desses estudantes em sala de aula, apontando alguns avanços na interpretação e na aprendizagem dos conceitos matemáticos, propostos por meio das tentativas de inclusão. Pesquisas como estas caminham na busca por

\footnotetext{
[...] reinventar a escola sem perda de qualidade, para incluir todos os alunos, sejam surdos, ouvintes ou com outras deficiências, constitui um grande desafio porque, essencialmente, exige a revisão do próprio conceito de escola. A finalidade da educação não deve ser apenas "funcional" para alcançar um estatuto social mais elevado e permitir a inserção no mercado de trabalho (PEIXOTO, 2015a, p. 41).
}

No que tange ao artigo P4, o questionamento foi "O que é dito em sala de aula e o que é interpretado pelo aluno surdo nas aulas de Matemática?", pois há o descompasso entre os sinais da intérprete e do professor, percebe-se um uso de termos inadequados no ensino de Matemática como, por exemplo, "cortar" e "passar para outro lado". Outro problema é a ausência de interação entre surdos e professores/estudantes ouvintes, característica do ensino tradicional. Todos esses fatores atrapalham ou impedem o aprendizado dos surdos com êxito.

$\mathrm{O}$ artigo P5 parte do questionamento "A ausência de alguns significados matemáticos (principalmente da geometria), no dicionário, podem interromper o ganho de conhecimento?", para mostrar que as negociações de alguns sinais para significados das figuras geométricas podem ajudar nas aulas de matemática.

O artigo P6 partiu de questionamentos voltados para o professor de Matemática e para 0 intérprete de Libras, respectivamente, com intuito de encontrar respostas sobre as dificuldades 
que ambos enfrentam em sala de aula para transmitir o conhecimento matemático, se a formação influencia, e o que pode ser melhorado.

Sendo assim, todas as pesquisas analisadas apresentam questionamentos voltados para os processos de ensino e de aprendizagem dos estudantes surdos buscando analisar suas diferentes concepções e abordagens. Sobre este processo, Peixoto (2015a, p. 52) destaca que

\begin{abstract}
a surdez, em si, não constitui deficiência, mas diferença na forma de ensino e aprendizagem; os surdos também apresentam semelhanças com ouvintes na construção de alguns conceitos, especialmente na fase inicial do desenvolvimento; a importância desde cedo da aquisição da Libras para favorecer as trocas simbólicas na interação com os elementos da nossa cultura; a exploração dessa língua, no ensino e aprendizagem da Matemática para facilitar a mediação semiótica e, por último, o desenvolvimento da visualidade do surdo através de atividades específicas e apropriadas.
\end{abstract}

No geral, percebeu-se uma preocupação dos autores das pesquisas analisadas sobre a questão do ensino e da aprendizagem de Matemática do estudante surdo, e anseios por encontrar estratégias didáticas que facilitem este processo.

\title{
5.4 Das metodologias utilizadas
}

Os artigos analisados trazem uma abordagem de investigação qualitativa. $\mathrm{O}$ foco geral se trata de identificar erros que isolam os alunos surdos dos processos de ensino e de aprendizagem da Matemática, para que seja possível buscar melhorias de interação e comunicação que proporcionem eficácia no processo.

Além da observação, geralmente realizada pelos pesquisadores em investigações qualitativas, os artigos P1, P2 e P3 apresentaram como instrumento principal de pesquisa um questionário composto por situações-problema, elaborado de forma que facilitasse o entendimento dos alunos surdos. A avaliação diagnóstica de P1 se fez por meio do questionário elaborado com base na teoria dos campos conceituais de Vergnaud. P2 aplicou as questões disponibilizando suportes de representação diferentes para cada situação enunciada, sendo estes, materiais concretos, lápis e papel e representação visual do problema.

No artigo P3, vale ressaltar, que os sujeitos foram submetidos, como forma de avaliação de competências numéricas, a realizar a Prova Conceitual de Resolução de Problemas Numéricos, 
de forma adaptada. Trata-se de um instrumento que utiliza objetos concretos sem o recurso da escrita; a realização da prova foi registrada em vídeo.

Os artigos P1, P4, P5 e P6, dentro da perspectiva da investigação qualitativa, utilizaram o método exploratório descritivo. Em P1, a constituição de dados inicialmente foi feita por meio de uma entrevista particular filmada; em P6, foi realizada entrevista semiestruturada gravada em áudio e transcrita na íntegra. Nas pesquisas P4 e P5 os encontros também foram filmados a fim de averiguar o perfil dos sujeitos e 0 ambiente.

O artigo P5 trata de um estudo de campo feito por observação participante sistemática estruturada, as descrições de interações na sala de aula foram baseadas em um sistema de transcrição que foi desenvolvido pelo grupo de pesquisa da Federação Nacional de Educação e Integração dos surdos (FENEIS), conhecido como sistema de notação em palavras.

Em todos os artigos analisados, os pesquisadores se fizeram presentes no lócus da pesquisa. Todos os trabalhos também foram realizados com embasamento documental de teses e dissertações que tratam do ensino de Matemática para surdos.

\subsection{Principais resultados e contribuições para o avanço do tema na área}

De acordo com a análise das pesquisas, muitas são as dificuldades enfrentadas pelos alunos surdos nas salas de aula, dessa forma a inclusão proposta na legislação não se mostra tão eficaz na prática. Como afirma Muniz (2018, p. 97), "é imprescindível que todo o corpo escolar esteja consciente do estudante que está recebendo, para que [...] possam assistir, de fato, esses estudantes, incluindo-os com equidade social e, principalmente, considerando suas características e especificidades de aprendizagem".

No que tange à resolução de problemas matemáticos, destaca-se como grande barreira a ser superada nos processos de ensino e de aprendizagem dos alunos surdos, a diferença da língua materna dos sujeitos envolvidos, Português e Libras, que impede a eficácia da interação/comunicação professor-aluno, entre outras particularidades.

Para Onuchic e Allevato (2011), a resolução de problemas representa um contexto bastante propício à construção de conhecimento matemático, a partir da observação e percepção de padrões, principalmente quando considerada como metodologia de ensino, ou seja, se o problema for proposto como gerador de novos conceitos e conteúdos matemáticos. No entanto, 
de nada adiantará se o estudante surdo não compreender o que está sendo trabalhado, nesse contexto, a utilização da Libras pelo professor e tradução eficaz do intérprete, é indispensável.

No artigo P1, foi identificado que nenhum dos alunos - todos surdos - conseguiu compreender o que era solicitado nos problemas escritos na Língua Portuguesa, alguns problemas só foram entendidos após a comunicação em Libras, sendo, ainda, necessárias explicações adicionais. No entanto, segundo os autores, essa dificuldade quanto à interpretação também pode ser vista em alunos ouvintes. Fez-se claro que os alunos surdos mesmo com as questões traduzidas em Libras, ainda sentiram dificuldades em traçar uma estratégia de resolução de problemas aditivos, apontando a necessidade de elaborar problemas específicos para desenvolver determinados conceitos matemáticos.

P2, que investigou problemas dentro da estrutura multiplicativa, expressou resultados nos quais concluiu-se que apresentar problemas matemáticos, até mesmo escritos em Português, aos alunos logo nos anos iniciais, contribui para que essas crianças adquiram mais facilidade na resolução de problemas multiplicativos, embora os resultados apontem que quando os enunciados são apresentados em Libras e na escrita dos surdos (interlíngua) facilitam ainda mais a compreensão do que está sendo proposto no problema, tanto para crianças instruídas sobre conceitos de multiplicação ou não, independe do nível de instrução.

Com relação aos materiais utilizados - material concreto, lápis e papel e representação visual —, nas resoluções dos problemas apresentados em Língua Portuguesa, os alunos surdos obtiveram um desempenho maior quando utilizaram lápis e papel como ferramenta de compreensão da forma escrita em Português, que é mais difícil de compreender do que a interlíngua ou a Libras.

Já P3 estabelece que a compreensão da situação-problema vai além do domínio das palavras e das operações aritméticas, ou seja, a dificuldade do surdo em resolução de situaçõesproblema não é devido à dificuldade no domínio do Português, na verdade todo aluno ouvinte ou surdo apresentará dificuldades com a interpretação dos problemas e precisará lidar com leitura funcional e com a questão da lógica do sistema numérico e de medidas. Os autores mostram ainda outros fatores do problema, como a maneira que a escola transmite o conhecimento matemático e a falta de domínio da Libras do professor que lida com o surdo. Essa pesquisa mostra que a negociação dos conceitos matemáticos e seus significados facilita a compreensão dos alunos surdos, sendo assim, a Libras deve ser utilizada como o instrumento de negociação dos conceitos. 
Em P4 foi observado que a Matemática apresentada, valorizando apenas técnicas oraisauditivas, dificultava a compreensão do estudante surdo pelo fato de não explorar sua "experiência visual". Destacou-se que a utilização de termos como "some, corta e tira", complicam a compreensão até mesmo daqueles que dominam a língua utilizada pela maioria da sala, prejudicando ainda mais a compreensão por parte de sujeitos que não a utilizam.

A questão não é buscar uma fala idêntica entre o professor de Matemática e o intérprete, até porque há muita dificuldade de se transitar por duas línguas diferentes, o que deve ser buscado é a identificação de onde e como a diferença pode influenciar na aprendizagem do aluno. Dessa forma, os autores entendem ser preciso haver uma boa interação entre os professores e os intérpretes, a relação de ambos deve ser considerada em todos os momentos, tanto na elaboração dos projetos pedagógicos quanto na produção dos planos de aulas. Quem está mais próximo dos alunos surdos e entende suas dificuldades especificas são os intérpretes e para analisar erros e acertos específicos de cada disciplina, o professor possui um conhecimento mais aprofundado para tal, portanto ambos precisam estar em constante comunicação para atingir o foco principal que é instigar a aprendizagem do aluno surdo, da maneira mais eficaz possível.

P5 trabalhou conceitos de geometria. Os alunos não conheciam formas geométricas no geral, no entanto, foi observado um aprendizado durante a experiência, mas vale ressaltar que só ocorreu devido a negociações em conjunto para a criação de sinais, ou seja, os estudantes precisaram de uma linguagem compartilhada que permitisse a comunicação e a explanação/discussão dos conceitos matemáticos.

Os resultados da pesquisa apontam que para o aluno surdo seria ideal uma escola onde os conteúdos curriculares fossem ministrados em Libras, sua língua de domínio, para que 0 desenvolvimento da aprendizagem pudesse ocorrer plenamente, porém mesmo que o professor tenha domínio da língua de sinais, ele vai necessitar traçar estratégias adequadas e criar um vocabulário específico para ensinar certos conceitos, pois é muito frequente que termos técnicos ou científicos não possuam um correlato em Libras, uma vez que só recentemente os surdos vêm conquistando o direito do acesso a estes níveis de conhecimento.

Os autores de P6 chegaram a vários resultados com foco nos intérpretes, observando a importância desses profissionais que, na maioria das vezes, acabam realizando não apenas a função que thes cabe, mas também a de professor dos alunos surdos. Primeiramente, percebeuse 0 quanto os cursos de formação de intérpretes precisam ser repensados, posto que muitos 
deles saem de ambientes diferentes dos escolares, o que ocasiona dificuldades nos processos de ensino e de aprendizagem em uma sala de aula. Os pesquisadores sugerem a formação de intérpretes por áreas, o que proporcionaria uma discussão específica de sinais para conceitos das diferentes disciplinas. Sugerem, também, que as semanas pedagógicas escolares proporcionem cursos aos intérpretes, em que os sinais específicos de todas as disciplinas possam ser compartilhados. Esses encontros devem envolver adultos surdos, principalmente aqueles que atuam como professores de Libras.

Outro ponto destacado em P6 como fator problema, trata-se das aulas de Matemática ainda serem ministradas com a prática de explicações orais e exercícios, por conta disso os intérpretes acabam precisando criar formas de traduzir esse ensino, buscando estratégias metodológicas diferenciadas, o que não é aconselhável, pois este papel cabe ao professor. Destaca-se também a importância da cobrança para que a legislação e as políticas públicas governamentais para a educação de surdos ocorram de fato. 0 intérprete deve interagir com familiares de alunos surdos, com intuito de informar da existência desses direitos, pois muitos desconhecem essas garantias. Por fim, a pesquisa constatou que os intérpretes não se envolvem nos planejamentos escolares e ressalta que sem essa parceria as especificidades dos alunos surdos não podem ser plenamente atendidas.

De um modo geral, todas as pesquisas apontam que os professores precisam conhecer as especificidades de cada aluno, particularmente para entender como aprendem e, a partir daí, desenvolver ações pedagógicas que busquem atender essas especificidades. Atentam para os prejuízos do ensino tradicional da Matemática e para a importância de os professores dominarem a língua de sinais (Libras) e possuírem conhecimentos básicos sobre a diversidade linguística que eles apresentam, para que desta forma haja interação, comunicação e os processos de ensino e de aprendizagem possam ocorrer sem maiores barreiras.

\section{Considerações}

Esta pesquisa teve como objetivo analisar pesquisas acadêmicas que tratam da inclusão de estudantes surdos e enfocam a resolução de problemas. Com base no Mapeamento da Pesquisa Educacional (BIEMBENGUT, 2008), foram selecionados e estudados seis artigos publicados em revistas dos estratos A1 a B2 do Qualis da Coordenação de Aperfeiçoamento de Pessoal de Nível Superior (CAPES) e indexados no Scielo. 
De acordo com o estudo, percebeu-se que a inclusão proposta na legislação não está acontecendo de forma tão eficaz na prática. Todos os artigos analisados apontam que ainda há uma grande lacuna entre a transmissão dos conteúdos matemáticos dos professores para os alunos surdos, e que embora a dificuldade com resolução de problemas não decorra somente da falta de domínio do Português — pois alunos ouvintes também apresentam dificuldades em interpretação -, é nítido que quando uma situação-problema é tratada na língua que os surdos dominam, facilita a compreensão, no entanto, não garante a eficácia na resolução.

Foram identificados muito mais problemas do que avanços; e vários são os fatores desses problemas, entre eles destaca-se a maneira com a escola transmite o conhecimento matemático — adotando tão somente a prática oral-auditiva, a qual acarreta prejuízos para a compreensão do aluno surdo; e a utilização de termos inexistentes em Libras acaba não explorando a "experiência visual", por exemplo. Outro fator importante é a falta de domínio da Libras por parte dos professores que trabalham com o surdo. O domínio de Libras facilita a negociação com os estudantes, principalmente no que se refere aos conceitos matemáticos e a descoberta pela metodologia mais efetiva para cada situação, sendo esta a melhor forma de mediação para os processos de ensino e de aprendizagem, porém ainda não comumente aplicada.

Como apontado nos artigos, o intérprete de Libras é indispensável em sala de aula, mas não é suficiente. Verificou-se ainda uma grande falha em relação à interação do intérprete com 0 professor de Matemática e com a escola, que se faz de extrema importância, pois estando 0 intérprete mais próximo do aluno surdo, o mesmo conhece melhor suas dificuldades específicas. É necessário, então, que o intérprete participe dos planejamentos de aulas nas reuniões escolares, das jornadas pedagógicas e de todo o contexto de programação escolar; dessa maneira poderão construir, em conjunto, metodologias mais eficazes nos processos de ensino e de aprendizagem do estudante surdo.

Por outro lado, o professor precisa entender que ele é o principal responsável pelo ensino e pela aprendizagem dos estudantes, inclusive dos estudantes surdos. Desse modo, não pode se abster de ensiná-lo tendo intérprete, ou não.

Em vista disso, pode-se dizer que a inclusão dos surdos nas escolas ainda não ocorre de fato. Para isso, é preciso que a interação e aprendizagem aconteçam, o que requer adequação da estrutura escolar e exercício do trabalho do professor. Sabe-se que as escolas brasileiras já enfrentam inúmeros problemas; com os professores não é diferente, todo um sistema precisa ser 
repensado. Portanto, para se obter avanços significativos na inclusão, os espaços de Atendimento Educacional Especializados (AEE) e as Salas de Recursos devem atuar efetivamente, apoiando professor e intérprete de Libras. Somente assim poderá ser possível que a inclusão aconteça.

\section{Referências}

ALLEVATO, Norma Suely Gomes. Novas reflexões sobre o ensino-aprendizagem de Matemática através da resolução de problemas. In: BICUDO, Maria Aparecida Viggiani. (Org.). Pesquisa em Educação Matemática: concepções e perspectivas. São Paulo: EdUNESP, 1999. p. 199-218.

ALLEVATO, Norma Suely Gomes; ONUCHIC, Lourdes de la Rosa. Ensino-aprendizagemavaliação de Matemática: por que através da Resolução de Problemas. In: ONUCHIC, Lourdes de la Rosa; ALLEVATO, Norma Suely Gomes; NOGUTI, Fabiane Cristina Höpner; JUSTULIN, Andressa Maria. (Org.). Resolução de Problemas: teoria e prática. Jundiaí: Paco Editorial, 2014, p. 35-52.

BARBOSA, Heloisa. O desenvolvimento cognitivo da criança surda focalizado nas habilidades visual, espacial, jogo simbólico e matemática. In: QUADROS, Ronice Müller; STUMPF, Marianne Rossi. (Org.). Estudos surdos IV. Petropólis: Arara Azul, 2001, p. 408-425.

BIEMBENGUT, Maria Sallet. Mapeamento na pesquisa educacional. Rio de Janeiro: Ciência Moderna, 2008.

BOGDAN, Robert C.; BIKLEN, Sari Knopp. Investigação qualitativa em Educação: uma introdução à teoria e aos métodos. Tradução de Maria João Alvarez, Sara Bahia dos Santos e Telmo Mourinho Baptista. Porto: Porto Editora, 1994.

BORGES, Fábio Alexandre. A educação inclusiva para surdos: uma análise do saber matemático intermediado pelo Intérprete de Libras. 2013. 262f. Tese (Doutorado em Educação para a Ciência e a Matemática) - Centro de Ciências Exatas. Universidade Estadual de Maringá. Maringá.

BOTELHO, Paula. Segredos e silêncios na interpretação dos surdos. Belo Horizonte: Autêntica, 1998.

BRASIL. Decreto $n^{\circ} 5.626$, de 22 de dezembro de 2005. Regulamenta a Lei $n^{0} 10.436$, de 24 de abril de 2002, e 0 art. 18 da Lei no 10.098, de 19 de dezembro de 2000. Brasília: Diário Oficial da União, 23 dez. 2005.

BRASIL. Decreto $n^{\circ} 6.571$, de 17 de setembro de 2008. Dispõe sobre o atendimento educacional especializado, regulamenta o parágrafo único do art. 60 da Lei no 9.394 , de 20 de dezembro de 1996, e acrescenta dispositivo ao Decreto n 6.253, de 13 de novembro de 2007. Brasília: Diário Oficial da União, 18 set. 2008.

BRASIL. Lei 10.436, de 24 de abril de 2002. Dispõe sobre a Língua Brasileira de Sinais - Libras e dá outras providências. Brasília: Diário Oficial da União, 24 abr. 2002. 
BRASIL. Lei n. ${ }^{9}$ 9.394, de 20 de dezembro de 1996. Brasília, 1996. Estabelece as diretrizes e bases da educação nacional. Brasília: Diário Oficial da União, 23 dez. 1996.

BRASIL. Lei ñ 13.146, de 6 de julho de 2015. Institui a Lei Brasileira de Inclusão da Pessoa com Deficiência (Estatuto da Pessoa com Deficiência). Brasília: Diário Oficial da União, 7 jul. 2015.

BRASIL. Ministério da Educação. Secretaria de Educação Básica. Base Nacional Comum Curricular. Brasilia: MEC/SEB, 2017.

BRASIL. Ministério da Educação. Secretaria de Educação Fundamental. Parâmetros Curriculares Nacionais: Matemática. Brasília: MEC/SEF, 1998.

CHICA, Cristiane Henrique Rodrigues. Por que formular Problemas? In: SMOLE, Kátia Stocco; DINIZ, Maria Ignez. (Org.) Ler, escrever e resolver problemas: habilidades básicas para aprender Matemática. Porto Alegre: Artmed, 2001, p. 151-174.

DANTE, Luiz Roberto. Didática da resolução de problemas de Matemática. 12. ed. São Paulo: Ática, 2000.

GABRILLI, Mara. Lei Brasileira de Inclusão - Estatuto da Pessoa com Deficiência: Lei 13.146/15. Brasília, 2016.

KRULIK, Stephen; REYS, Robert E. (Org.). A resolução de problemas na matemática escolar. Tradução de Hygino Hugueros Domingues. São Paulo. Atual, 1997.

LACERDA, Cristina Broglia Feitosa. A inserção da criança surda em classe de crianças ouvintes: focalizando a organização do trabalho pedagógico. In: $23^{a}$ REUNIÃO ANUAL DA ASSOCIAÇÃO NACIONAL DE PÓS-GRADUAÇÃO E PESQUISA EM EDUCAÇÃO, 2000, Caxambú. Anais da $23^{a}$ Reunião da ANPEd. Caxambú: ANPED, 2000, p. 1-17.

MALHEIROS, Ana Paula dos Santos. A produção matemática dos alunos em um ambiente de modelagem. 2004. 180f. Dissertação (Mestrado em Educação Matemática) - Instituto de Geociências e Ciências Exatas. Universidade Estadual Paulista, Rio Claro.

MEAD, George Herbert. L'esprit, le soi et la société. Traduit de i'nglais par Jean Cazeneuve, Eugène Kaelin et Georges Thibault. Paris: Presses Universitaries de France, 1963.

MOREIRA, Maria. Funções da interação verbal em contexto pedagógico. Revista Comunicare, Porto, n. 2, p. 17-24, 1997.

MUNIZ, Salvador Cardoso Silva. A inclusão de surdos nas aulas de Matemática: uma análise das relações pedagógicas envolvidas na tríade professora - intérprete - surdo. 2018. 118f. Dissertação (Mestrado em Educação Matemática) - Departamento de Ciências Exatas e Tecnológicas. Universidade Estadual de Santa Cruz, llhéus.

MUNIZ, Salvador Cardoso Silva; PEIXOTO, Jurema Lindote Botelho; MADRUGA, Zulma Elizabete de Freitas. Desafios da inclusão de surdos na aula de Matemática. Cocar, Belém, v. 12, n. 23, p. 215-239, jan./jun. 2018. 
NUNES, Terezinha; CAMPOS, Tânia; MAGINA, Sandra; BRYANT, Peter. Educação Matemática: números e operações numéricas. São Paulo: Cortez, 2001.

OLIVEIRA, Janine Soares. A comunidade surda: perfil, barreiras e caminhos promissores no processo de ensino-aprendizagem em Matemática. 2005. 78f. Dissertação (Mestrado em Ensino de Ciências e Matemática) - Departamento de Pesquisa e Pós-Graduação. Centro Federal de Educação Tecnológica Celso Suckow da Fonseca. Rio de Janeiro.

ONUCHIC, Lourdes de la Rosa. Ensino-Aprendizagem de Matemática através da Resolução de Problema. In: BICUDO, Maria Aparecida Viggiani. (Org.). Pesquisa em Educação Matemática: concepções e perspectivas. São Paulo: EdUNESP, 1999, p. 199-218.

ONUCHIC, Lourdes de la Rosa; ALLEVATO, Norma Suely Gomes. Novas reflexões sobre o ensino-aprendizagem de Matemática através da resolução de problemas. In: BICUDO, Maria Aparecida Viggiani; BORBA, Marcelo de Carvalho. (Org.). Educação Matemática: pesquisa em movimento. São Paulo: Cortez, 2008, p. 213-231.

ONUCHIC, Lourdes de la Rosa; ALLEVATO, Norma Suely Gomes. Pesquisa em resolução de problemas: caminhos, avanços e novas perspectivas. Bolema, Rio Claro, v. 25, n. 41, p. 73-98, dez. 2011.

PEIXOTO, Jurema Lindote Botelho. A negociação de significados e a emergência da ZDP na interação professor de Matemática, intérprete e aluno surdo. In: ALMEIDA, Wolney Gomes. (Org). Educação de surdos: formação, estratégias e prática docente. Ilhéus: Editus, 2015b, p. 137-161.

PEIXOTO, Jurema Lindote Botelho. Análise dos esquemas de surdos sinalizadores associados aos significados da divisão. 2015a. 266f. Tese (Doutorado em Difusão do Conhecimento) Faculdade de Educação. Universidade Federal da Bahia. Salvador.

POLYA, George. A arte de resolver problemas. Tradução e adaptação de Heitor Lisboa de Araújo. Rio de Janeiro: Interciência, 1995.

RAZUCK, Renata Cardoso de Sá Ribeiro; TACCA, Maria Carmen Villela Rosa; TUNES, Elisabeth. A pessoa surda e suas possibilidades no processo de aprendizagem e escolarização. Linguagens, Educação e Sociedade, Teresina, v. 12, n. 16, n. 1, p. 9-18, jan./jun. 2007.

RODRIGUES, David. Educação Inclusiva: mais qualidade à diversidade. In: RODRIGUES, David; KREBS, Ruy; FREITAS, Soraia Napoleão. (Org.). Educação inclusiva e necessidades educacionais especiais. Santa Maria: EdUFSM, 2005, p. 85-111.

SALES, Elielson Ribeiro. A visualização no ensino de Matemática: uma experiência com alunos surdos. 2013. 235f. Tese (Doutorado em Educação Matemática) - Instituto de Geociências e Ciências Exatas. Universidade Estadual Paulista. Rio Claro.

VYGOTSKY, Lev Semenovich. A formação social da mente: o desenvolvimento dos processos psicológicos superiores. Tradução de José Cipolla Neto, Luís Silveira Menna Afeche e Solange Castro Afeche. São Paulo: Martins Fontes, 2007. 